\title{
Valve repair improves the outcome of surgery for chronic severe aortic regurgitation: A propensity score analysis
}

\author{
Christophe de Meester, MS, ${ }^{\mathrm{a}, \mathrm{b}}$ Agnès Pasquet, MD, PhD, ${ }^{\mathrm{a}, \mathrm{b}}$ Bernhard L. Gerber, MD, PhD, \\ David Vancraeynest, MD, PhD, ${ }^{\mathrm{a}, \mathrm{b}}$ Philippe Noirhomme, MD, ${ }^{\mathrm{a}, \mathrm{c}}$ Gébrine El Khoury, MD, ${ }^{\mathrm{a}, \mathrm{c}}$ and \\ Jean-Louis J. Vanoverschelde, $\mathrm{MD}, \mathrm{PhD}^{\mathrm{a}, \mathrm{b}}$
}

\begin{abstract}
Background: For patients with aortic regurgitation (AR), aortic valve (AV) repair represents an attractive alternative to $\mathrm{AV}$ replacement (AVR), because it does not expose patients to the risk of prosthetic valve complications. Although the durability of AV repair has been documented, its prognosis has not yet been compared with prognosis of AVR.
\end{abstract}

\begin{abstract}
Methods: We performed a propensity score analysis to match patients who underwent surgical correction of severe AR by either AVR or AV repair between 1995 and 2012. After matching, 44 pairs of patients were compared regarding baseline characteristics; overall survival; operative survival; cardiac events, including reoperations; recurrent AR; and New York Heart Association functional class at final follow-up.
\end{abstract}

\begin{abstract}
Results: Operative mortality was similar in the AV repair and AVR groups ( $2 \%$ vs $5 \% ; P=.56)$. Kaplan-Meier survival analysis indicated a significantly better overall 9-year survival after AV repair than after AVR ( $87 \%$ vs $60 \% ; P=.007)$. Cox proportional survival analysis demonstrated that the choice of treatment was an independent predictor of postoperative survival. Finally, AV repair resulted in a slight increase, albeit not statistically significant, in reoperation rate $(8 \%$ vs $2 \% ; \log \operatorname{rank} P=.35)$.
\end{abstract}

Conclusions: AV repair significantly improves postoperative outcomes in patients with AR and whenever feasible should probably be the preferred mode of surgical correction. (J Thorac Cardiovasc Surg 2014;148:1913-20)

Aortic valve (AV) replacement (AVR) is an established treatment for patients with severe $\mathrm{AV}$ regurgitation (AR) ${ }^{1,2}$ AVR improves prognosis and quality of life, but exposes patients to a variety of prosthesis-related complications. ${ }^{3}$ Mechanical valves are associated with the risks of thromboembolism, valve thrombosis, and anticoagulationrelated bleeding, whereas biological valve substitutes undergo structural degeneration and expose patients to the risk of reoperation. ${ }^{4}$ The risk of prosthetic valve endocarditis also remains for both biological and mechanical substitutes. Taken together, the cumulative risk of valve-related complications has been estimated to be around $50 \%$ at 10 years in patients undergoing AVR for the treatment of $\mathrm{AR}^{4,5}$

In recent years, repair techniques for diseased AVs have received increasing attention, with the perception that

\footnotetext{
From the Pôle de Recherche Cardiovasculaire, Institut de Recherche Expérimentale et Clinique, ${ }^{\mathrm{a}}$ Université catholique de Louvain; and the Divisions of Cardiology ${ }^{\mathrm{b}}$ and Cardiothoracic Surgery, ${ }^{c}$ Cliniques Universitaires Saint-Luc, Brussels, Belgium.

Supported by the Fonds National de la Recherche Scientifique, Brussels, Belgium. Disclosures: Authors have nothing to disclose with regard to commercial support.

Received for publication Nov 10, 2013; revisions received Jan 3, 2014; accepted for publication Feb 3, 2014; available ahead of print March 20, 2014.

Address for reprints: Jean-Louis J. Vanoverschelde, MD, PhD, Division of Cardiology, Cliniques Universitaires Saint-Luc, Ave Hippocrate 10-2881, B-1200 Brussels, Belgium (E-mail: jean-louis.vanoverschelde@uclouvain.be). 0022-5223/\$36.00

Copyright (c) 2014 by The American Association for Thoracic Surgery http://dx.doi.org/10.1016/j.jtcvs.2014.02.010
}

maintaining the normal architecture of the AV apparatus would be beneficial to the patient. ${ }^{6-9}$ Thanks to innovations in operative techniques, ${ }^{9}$ an improved understanding of the functional anatomy of the aortic valve and root, ${ }^{10}$ as well as increased awareness of the mechanisms leading to $\mathrm{AR},{ }^{11} \mathrm{AV}$ repair has progressively evolved from an anecdotal approach to a plausible alternative to AVR. Several studies have indeed demonstrated that AV repair is feasible in a majority of patients with AR due to aortic root diseases or cusp prolapses and results in a low incidence of valve-related complications, including reoperations. $^{7-12}$ Despite these promising results, it is still uncertain if reconstruction of the $\mathrm{AV}$ provides survival advantages over AVR, as observed in mitral valve surgery.

We examined the outcome after AV repair or AVR in patients with severe AR, hypothesizing that AV repair would improve overall survival compared with AVR. Because comparison between these 2 operative approaches can be obscured by differences in baseline characteristics, the technique of propensity score matching was used to reduce selection bias and heterogeneity in the study population.

\section{METHODS \\ Study Population}

The study population consisted of 942 consecutive patients who underwent surgical correction of AR or for dilation of the ascending aorta between January 1, 1995, and December 31, 2012. Exclusion criteria (Figure 1) were missing preoperative data $(\mathrm{n}=47)$, AV surgery without severe AR, primary surgery for dilation of the ascending aorta, coronary 


\section{Abbreviations and Acronyms \\ $\mathrm{AR}=$ aortic regurgitation \\ $\mathrm{AV}=$ aortic valve \\ AVR $=$ aortic valve replacement \\ NYHA $=$ New York Heart Association}

artery bypass graft surgery, mitral regurgitation, tricuspid regurgitation, or myxoma $(\mathrm{n}=307)$.

Among 588 patients with severe AR, those aged $<18$ years $(\mathrm{n}=24)$; severe acute AR due to endocarditis or aortic dissection ( $\mathrm{n}=81$ ); concomitant severe mitral regurgitation or aortic stenosis $(n=42)$; a nondilated left ventricle, defined as a $\mathrm{LV}$ end-diastolic dimension $<32 \mathrm{~mm} / \mathrm{m}$ height $(\mathrm{n}=49)^{13}$; prior valve surgery $(\mathrm{n}=69)$; glomerular filtration rate $<30$ $\mathrm{mL} / \mathrm{min}(\mathrm{n}=4)$; or a life expectancy $<1$ year in the absence of AR $(n=3)$ were secondarily excluded. Patients undergoing a Ross procedure were excluded as well $(n=31)$. Patients who had coronary artery disease or had previously undergone coronary artery bypass graft surgery were not excluded.

\section{Group Selection}

To reduce the effect of treatment selection bias, a propensity score analysis was performed. ${ }^{14,15}$ The propensity score was estimated by use of a multiple logistic regression model where treatment was the dependent variable, and plausible correlates of either the therapeutic decision or survival acted as independent variables. The 5 covariables used to build the propensity score were age, New York Heart Association (NYHA) functional class I-II, presence of bicuspid AV, ejection fraction, and the mechanism of AR. The calculated propensity scores were then used to select pairs of patients with matched propensity scores in the 2 treatment groups (1:1 match) within a caliper of 0.15 standard deviations of the propensity score, using STATA 10.0 software (Stata Corporation, College Station, Tex) and the psmatch routine. The propensity score yielded 44 matched pairs of patients.

Information on postoperative events and functional class was obtained for all patients between January and April 2013. Cardiac events and causes of death were ascertained by contacting the patients' physicians, the patients themselves if alive or their family, and by reviewing death certificates. Follow-up was $97 \%$ complete.

\section{Echocardiography}

Preoperative and follow-up echocardiographic examinations were performed using commercially available ultrasound systems. All patients underwent a comprehensive examination, including M-mode and 2-dimensional echocardiography, as well as conventional and color Doppler examinations. All tests were conducted by experienced echocardiographers.

The severity of AR was assessed semiquantitatively on a scale of $1+$ to $4+$ by an integrated approach that included the size of the regurgitant jet in the left ventricular cavity; the proximal regurgitant jet width; the jet deceleration rate; the magnitude of the diastolic flow reversal in descending aorta; the size of the proximal convergence zone; and, when available, the regurgitant volume and the effective regurgitant orifice area. Severe AR was defined as grade $3+\mathrm{AR}$ or greater. The approach to semiquantification used in our study is in agreement with prevailing guidelines at the time of examination. ${ }^{16}$

\section{Surgical Procedures}

The choice of surgical technique was left at the discretion of the attending surgeon who took into account the referring physicians' and the patients' preferences. The choice between an attempt to valve repair, without any guarantee in terms of long-term results, and AVR was clearly presented to every patient and referring physician. Although the majority of patients accepted the risk and underwent AV repair, a few patients refused and preferred to undergo AVR.

Surgical repair of the AV involved a variety of techniques tailored to each individual dysfunction identified. These techniques have been extensively described elsewhere. ${ }^{10}$ The prostheses used in AVR were mechanical in 15 patients and biological in 29 patients. The choice of prosthesis was discussed in detail among the informed patient, his or her cardiologist, and the surgeon, in accordance with prevailing guidelines. In general, bioprosthetic AVR was proposed to patients aged 65 years or older, whereas mechanical AVR was preferred in patients younger than age 60 years. Between the ages of 60 and 65 years, both substitutes were usually proposed and the final choice took into account possible contraindications and patients' preferences.

\section{Statistical Analysis}

All statistical analyses were performed using SPSS version 20.0 software (IBM-SPSS Inc, Armonk, NY). Continuous variables were expressed as mean \pm 1 standard deviation, with categorical variables as counts and percentages. To compare groups, student paired $t$ test or McNemar $\chi^{2}$ tests were used when appropriate.

A Cox proportional-hazards survival model for matched data was built for determination of the factors independently associated with outcome. For the univariate analysis, all clinical, angiographic, and echocardiographic variables were proposed for inclusion. Variables with $P<.10$ were subsequently submitted to a multivariate Cox proportional-hazards survival model. For this purpose, a preliminary model was built from which the choice of treatment was excluded. The ability of the choice of treatment to improve the prediction of death by this preliminary model was then tested.

Cardiovascular events and reoperation-free survivals in the 2 treatment groups were computed using the Kaplan-Meier method and compared using the log-rank $\chi^{2}$ test. For each patient included in the study, the corresponding average age- and gender-specific annual mortality rates of the Belgian general population were obtained and an expected survival curve was constructed.

The authors had full access to and take full responsibility for the integrity of the data. All authors read and agreed to the article as written.

\section{RESULTS}

The strategy of the analysis was to compare the matched AV repair group with the AVR group regarding baseline characteristics of the patients; overall survival; operativefree survival; and survival free of cardiac events, including reoperations, recurrent $\mathrm{AR}$, and NYHA functional class at last follow-up.

\section{Baseline Characteristics}

Table 1 shows the baseline demographic and clinical characteristics of the study population. Baseline hemodynamic and echocardiographic characteristics are shown in Table 2. Operative data are shown in Tables 3 and 4.

Indications for surgery were presence of symptoms ( $\mathrm{n}=32,8$ for NYHA functional class II symptoms and 24 NYHA class III-IV symptoms), asymptomatic dilation of the ascending aorta $(n=15)$, asymptomatic left ventricular dysfunction $(n=6)$, and asymptomatic left ventricular dilation $(\mathrm{n}=35)$. 


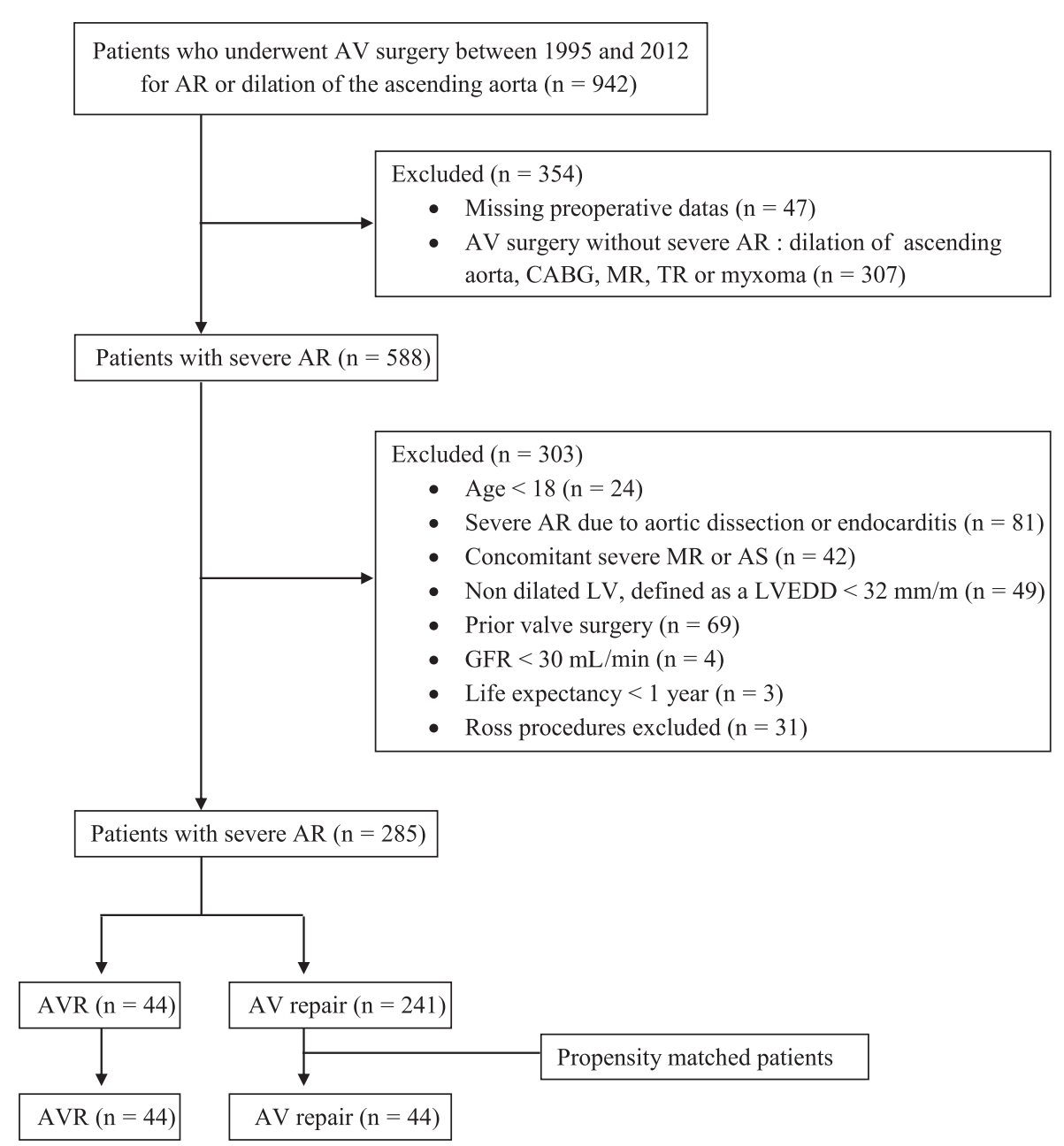

FIGURE 1. Flow chart of the study population. $A V$, Aortic valve; $A R$, aortic regurgitation; $C A B G$, coronary artery bypass graft; $M R$, mitral regurgitation; $T R$, tricuspid regurgitation; $A S$, aortic stenosis; $L V$, left ventricle; $L V E D D$, left ventricular end diastolic diameter; $G F R$, glomerular filtration rate; $A V R$, aortic valve replacement.

\section{Overall and Cardiovascular Survival}

During a mean follow-up of $6.8 \pm 4.7$ years, 23 patients died, 7 in AV repair group (2 heart failure, 1 postoperative, and 4 noncardiovascular deaths) and 16 in the AVR group (4 heart failure, 4 sudden deaths, 2 postoperative, 1 stroke, 2 miscellaneous, and 3 noncardiovascular deaths). As shown in Figure 2, 9-year overall survival was significantly better after AV repair than after AVR $(87 \% \pm 6 \%$ vs $60 \% \pm 9 \% ; P=.007)$. At 9 years, the cardiovascular survival was also superior to that after AVR $(91 \% \pm 5 \%$ vs $66 \% \pm 9 \%$; log rank $P=.009$ ).

For the multivariate Cox proportional hazards analysis, we first built a preliminary survival model where all the demographic and clinical variables except treatment choice were proposed for inclusion. This preliminary model identified age $(P<.001)$ and NYHA functional class I-II $(P=.047)$ as factors independently associated with outcome. The ability of the choice of treatment to improve the prediction of death by this preliminary model was then tested. As indicated in Table 5, the choice of treatment added significant prognostic information to that provided by the 2 covariates initially retained in the model. All 3 covariates independently contributed to long-term survival with a significant benefit for AV repair (hazard ratio [HR], 0.11; 95\% confidence interval, 0.03-0.40; $P=.001)$.

The propensity score was also entered together with the treatment choice into a bivariate Cox proportional hazards regression model to estimate the 9-year propensity scoreadjusted HR associated with the choice of treatment. In this analysis as well, AV repair was found to provide a significant survival advantage over AVR (HR, 0.10; 95\% confidence interval, 0.03-0.36; $P=.001$ ).

\section{Operative Mortality}

Operative death was defined as a death occurring within 1 month of surgery or during the same hospitalization. Operative death occurred in 1 of 44 patients in the AV repair group $(2 \%)$ compared with 2 of 44 patients in the AVR group $(5 \%)(P=.56)$. 
TABLE 1. Baseline demographic and clinical characteristics

\begin{tabular}{|c|c|c|c|c|c|}
\hline \multirow[b]{2}{*}{ Characteristic } & \multicolumn{2}{|c|}{ Aortic valve repair $(n=44)$} & \multicolumn{2}{|c|}{ Aortic valve replacement $(n=44)$} & \multirow[b]{2}{*}{$P$ value } \\
\hline & n or mean \pm SD & Range or $\%$ & $\mathbf{n}$ & Range or $\%$ & \\
\hline Age (mean y \pm SD) & $65 \pm 10$ & $40-81$ & $63 \pm 12$ & $36-82$ & .45 \\
\hline Male gender & 32 & 72.7 & 36 & 81.8 & .45 \\
\hline Smoking habits & 13 & 29.5 & 17 & 38.6 & .48 \\
\hline Hypertension & 25 & 56.8 & 24 & 54.5 & $>.99$ \\
\hline Diabetes mellitus & 4 & 9.1 & 5 & 11.4 & $>.99$ \\
\hline Hypercholesterolemia & 18 & 40.9 & 13 & 29.5 & .38 \\
\hline Prior PCI or CABG & 1 & 2.3 & 0 & 0.0 & - \\
\hline Prior AMI & 1 & 2.3 & 2 & 4.5 & $>.99$ \\
\hline Prior stroke & 2 & 4.5 & 2 & 4.5 & $>.99$ \\
\hline PVD & 2 & 4.5 & 2 & 4.5 & $>.99$ \\
\hline COPD & 7 & 15.9 & 4 & 9.1 & .55 \\
\hline Preoperative atrial fibrillation & 4 & 9.1 & 6 & 13.6 & .75 \\
\hline GFR $($ mean $\mathrm{mL} / \mathrm{min} \pm \mathrm{SD})$ & $79 \pm 27$ & $31-165$ & $80 \pm 35$ & $31-149$ & .82 \\
\hline NYHA functional class I-II & 32 & 72.7 & 32 & 72.7 & $>.99$ \\
\hline
\end{tabular}

$S D$, Standard deviation; $P C I$, percutaneous coronary intervention; $C A B G$, coronary artery bypass graft; $A M I$, acute myocardial infarction; $P V D$, peripheral vascular disease; $C O P D$, chronic obstructive pulmonary disease; GFR, glomerular filtration rate; NYHA, New York Heart Association.

\section{Cardiovascular Events}

During follow-up, 29 patients experienced 1 or more cardiovascular events, 11 in the AV repair group (3 cardiovascular deaths, 3 reoperations, 1 stroke, 1 transplantation, 1 septicemia, and 2 other vascular events), and 18 in the AVR group (13 cardiovascular deaths, 1 reoperation on the aortic valve, 1 major bleed, 1 transplantation, 1 heart failure, and 1 percutaneous coronary intervention). As shown in Figure 3, cardiovascular event-free survival tended to be better in the AV repair group than in the AVR group $(68 \% \pm 8 \%$ vs $45 \% \pm 11 \%$; $P=.30$ ).

During follow-up, 4 patients needed an aortic valve reoperation; 3 in the $\mathrm{AV}$ repair group for recurrent severe AR and 1 in the AVR group for endocarditis. In the AV repair group, the mechanisms of recurrent $\mathrm{AR}$ were rupture of the right coronary sinus into the right atrium in 1 patient, scarring and calcification in another patient, and residual prolapse in the remaining patient. As shown in Figure 4, 9-year reoperation-free survival tended to be lower in the AV repair group than in the AVR group $(92 \% \pm 4 \%$ vs $98 \% \pm 2 \%$; $P=.35$ ).

\section{Echocardiographic Follow-up}

Complete echocardiographic follow-up data could be obtained in all but 19 patients (14 deaths, 3 lost for follow-up, and 2 living abroad). At the latest echocardiographic visit, none of the 28 AVR patients displayed more than trace $(\mathrm{n}=11)$ or $1+$ residual $(\mathrm{n}=17)$ AR. By contrast, among the $41 \mathrm{AV}$ repair patients $6(15 \%)$ exhibited no or trivial AR, 21 (51\%) had $1+$ residual AR, $11(27 \%)$ had $2+$ residual $\mathrm{AR}$, and $3(7 \%)$ had $3+$ residual AR. As mentioned earlier, all 3 patients with $3+$ residual AR subsequently underwent reoperation. Freedom from aortic insufficiency greater than grade $2+$ in AV repair was $68 \%$ at 9 years.

\section{NYHA Functional Class}

At long-term follow-up, NYHA functional class was similar in the AV repair and AVR groups $(1.3 \pm 0.6$ vs $1.2 \pm 0.5 ; P=.18)$.

TABLE 2. Baseline hemodynamic and echocardiographic data

\begin{tabular}{|c|c|c|c|c|c|}
\hline \multirow[b]{2}{*}{ Characteristic } & \multicolumn{2}{|c|}{ Aortic valve repair $(n=44)$} & \multicolumn{2}{|c|}{ Aortic valve replacement $(n=44)$} & \multirow[b]{2}{*}{$P$ value } \\
\hline & n or mean \pm SD & Range or $\%$ & n or mean \pm SD & Range or $\%$ & \\
\hline Heart rate (bpm) & $71 \pm 15$ & $41-107$ & $70 \pm 14$ & $42-100$ & .67 \\
\hline Systolic blood pressure (mm Hg) & $142 \pm 22$ & $100-190$ & $143 \pm 27$ & $90-190$ & .82 \\
\hline Diastolic blood pressure (mm Hg) & $60 \pm 14$ & $30-85$ & $56 \pm 14$ & $30-90$ & .11 \\
\hline LV end-diastolic dimensions ( $\mathrm{mm}$ ) & $64 \pm 8$ & $52-91$ & $66 \pm 8$ & $50-87$ & .11 \\
\hline LV end-systolic dimensions (mm) & $45 \pm 9$ & $29-73$ & $47 \pm 9$ & $32-66$ & .27 \\
\hline LV ejection fraction $(\%)$ & $52 \pm 13$ & $25-84$ & $52 \pm 13$ & $19-72$ & .90 \\
\hline $\mathrm{CAD}$ & 13 & 29.5 & 11 & 25.0 & .80 \\
\hline Euroscore $(\%)$ & $7 \pm 7$ & $2-33$ & $6 \pm 8$ & $2-38$ & .99 \\
\hline
\end{tabular}

$S D$, Standard deviation; $L V$, left ventricular; $C A D$, coronary artery disease. 
TABLE 3. Operative and postoperative data

\begin{tabular}{|c|c|c|c|c|c|}
\hline \multirow[b]{2}{*}{ Characteristic } & \multicolumn{2}{|c|}{ Aortic valve repair $(n=44)$} & \multicolumn{2}{|c|}{ Aortic valve replacement $(n=44)$} & \multirow[b]{2}{*}{$P$ value } \\
\hline & n or mean \pm SD & Range or $\%$ & n or mean \pm SD & Range or $\%$ & \\
\hline Crossclamp time (min) & $86 \pm 33$ & $32-167$ & $94 \pm 36$ & $25-205$ & .22 \\
\hline ECC time (min) & $111 \pm 42$ & $42-222$ & $122 \pm 49$ & $40-254$ & .21 \\
\hline \multicolumn{6}{|l|}{ Associated procedures } \\
\hline CABG & 9 & 20.5 & 12 & 27.3 & .58 \\
\hline No. of arterial grafts per patient & 0.83 & $0-1$ & 0.75 & $0-1$ & - \\
\hline Mitral valve repair & 4 & 9.1 & 6 & 13.6 & .73 \\
\hline Aortic root replacement & 23 & 52.3 & 16 & 36.4 & .12 \\
\hline \multicolumn{6}{|l|}{ Timing of surgery } \\
\hline Elective & 43 & 97.7 & 43 & 97.7 & $>.99$ \\
\hline Urgent & 1 & 2.3 & 1 & 2.3 & $>.99$ \\
\hline Emergent & 0 & 0.0 & 0 & 0.0 & - \\
\hline \multicolumn{6}{|l|}{ Aortic valve anatomy } \\
\hline Tricuspid & 39 & 88.6 & 36 & 81.8 & .55 \\
\hline Bicuspid & 5 & 11.4 & 8 & 18.2 & .55 \\
\hline \multicolumn{6}{|l|}{ Mechanism of atrial repair } \\
\hline Type 1 dysfunction & 12 & 27.3 & 16 & 36.4 & .52 \\
\hline Type 2 dysfunction & 14 & 31.8 & 10 & 22.7 & .45 \\
\hline Type 3 dysfunction & 18 & 40.9 & 18 & 40.9 & $>.99$ \\
\hline
\end{tabular}

\section{DISCUSSION}

In patients with severe mitral regurgitation, mitral valve repair has been shown to provide both a low operative risk and an excellent late survival, with a low incidence of valve-related complications. These results are at variance with those obtained with mitral valve replacement. ${ }^{17}$ Accordingly, mitral valve repair, if feasible, has become the preferred option for treating patients with severe mitral regurgitation. ${ }^{1,2}$ Since the early days of cardiac surgery, AV repair has also been attempted for treating patients with severe AR, but the results have been quite varied. Thanks to innovations in operative techniques ${ }^{9}$ and a better understanding of the functional anatomy of the aortic valve and root, ${ }^{10}$ the immediate results of $\mathrm{AV}$ reconstructive surgery have dramatically improved. Although the durability of

TABLE 4. Surgical repair techniques used in the different aortic valve dysfunctional subsets

\begin{tabular}{lccc}
\hline \multicolumn{1}{c}{ Correction performed } & $\begin{array}{c}\text { Type 1 } \\
(\mathbf{n}=\mathbf{1 2})\end{array}$ & $\begin{array}{c}\text { Type 2 } \\
(\mathbf{n}=\mathbf{1 4})\end{array}$ & $\begin{array}{c}\text { Type 3 } \\
(\mathbf{n}=\mathbf{1 8})\end{array}$ \\
\hline Root procedures & & & \\
$\quad$ Root reimplantation & 10 & 4 & 8 \\
$\quad$ Root remodeling & 1 & 1 & 1 \\
$\quad$ Supracoronary replacement & 0 & 0 & 1 \\
Cuspal procedures & & & \\
$\quad$ Free edge plication & 3 & 7 & 7 \\
$\quad$ Resection & 0 & 2 & 6 \\
$\quad$ Shaving/decalcification & 1 & 1 & 2 \\
$\quad$ Free edge reinforcement & 0 & 8 & 6 \\
$\quad$ Patch extension & 0 & 0 & 2 \\
Subcommisural annuloplasty & 3 & 9 & 7 \\
\hline
\end{tabular}

this approach has also been documented, its superiority to prosthetic valve replacement has not yet been established. Our consecutive series is the first to directly compare AV repair and AVR for the treatment of severe AR. We found that patients undergoing surgical correction of severe AR incur a low operative mortality, both after AV repair and AVR; patients undergoing AV repair have a significantly better long-term overall and cardiovascular survival than

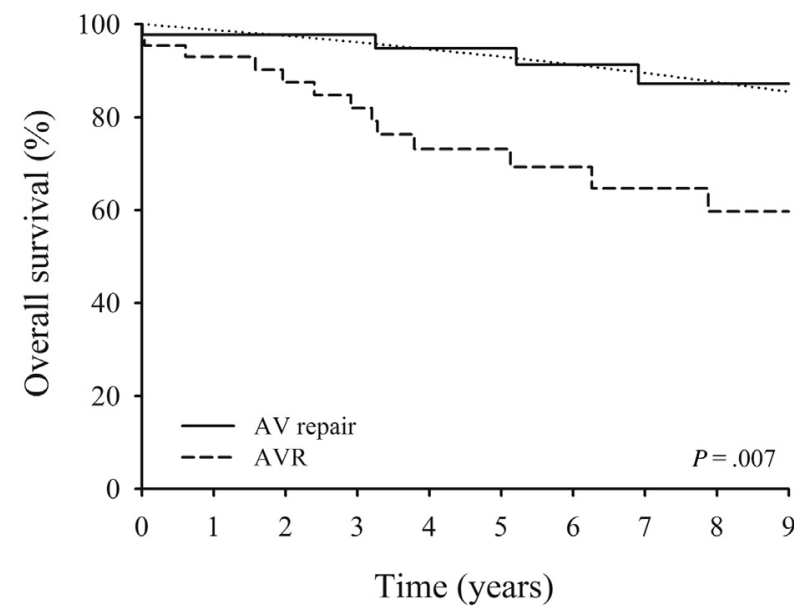

$\begin{array}{lllllllllll}\text { AV repair } & 44 & 41 & 39 & 35 & 31 & 28 & 26 & 22 & 17 & 13 \\ \text { AVR } & 44 & 38 & 33 & 30 & 24 & 20 & 17 & 15 & 13 & 11\end{array}$

FIGURE 2. Kaplan-Meier survival curves comparing overall postoperative survival among patients undergoing aortic valve $(A V)$ repair (solid line) or aortic valve replacement (AVR) (dashed line). Numbers at bottom indicate patients at risk. The dotted line shows the survival of the ageand gender-matched Belgian population. 
TABLE 5. Additional prognostic value of aortic regurgitation repair by use of Cox proportional hazards analysis

\begin{tabular}{lcrrrrr}
\hline & \multicolumn{3}{c}{ Initial model } & & \\
\cline { 2 - 4 } \multicolumn{1}{c}{ Covariate } & $\begin{array}{c}\text { Hazard ratio } \\
(\mathbf{9 5} \% \mathbf{C I})\end{array}$ & $\begin{array}{c}\boldsymbol{\chi}^{\mathbf{2}} \text { to } \\
\text { remove }\end{array}$ & $\begin{array}{c}\boldsymbol{P} \text { value } \\
\boldsymbol{\chi}^{\mathbf{2}} \text { to } \\
\text { enter }\end{array}$ & $\boldsymbol{P}$ value \\
\hline Age (per y) & $1.17(1.08-1.26)$ & 23.1 & $<.001$ & & \\
NYHA functional & $0.38(0.15-0.99)$ & 3.7 & .047 & & \\
$\quad \begin{array}{ll}\quad \text { class I-II } \\
\text { Aortic valve repair }\end{array}$ & & & & & 14.0 & $<.001$ \\
\hline CI, Confidence interval; $N Y H A$, New York Heart Association. & &
\end{tabular}

similar patients undergoing AVR (they also experience fewer cardiovascular events); and AV repair results in a slightly increased, albeit not statistically significant, longterm risk of reoperation compared with AVR.

\section{AV Repair for the Treatment of AR}

Although AVR remains the gold standard for the surgical correction of AR, the clinical applicability of AV repair has recently gained momentum. The clinical imperatives driving the push for $\mathrm{AV}$ repair are primarily to avoid the risk of prosthetic valve complications such as thromboembolism, endocarditis, bleeding, and structural valve deterioration, which altogether occur at a pace of $2 \%$ to $7 \%$ per year. $^{4,5}$

Although techniques of $\mathrm{AV}$ repair have been documented for more than 40 years, their use has remained anecdotal until the development and dissemination of valve-sparing aortic root replacement procedures during the early 1990s. ${ }^{18,19}$ Initially designed for the treatment of type 1 $\mathrm{AV}$ dysfunction; that is, aortic root dilation, these

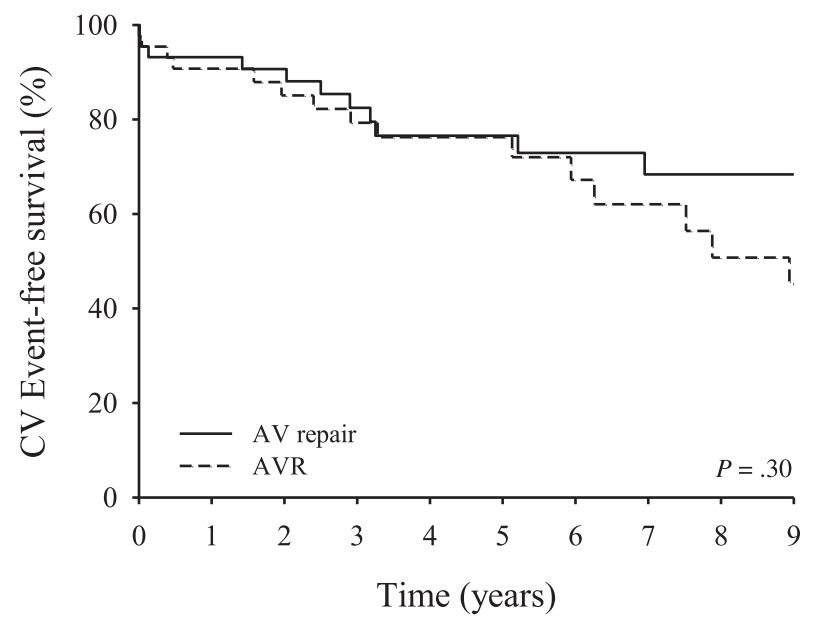

$\begin{array}{lllllllllll}\text { AV repair } & 44 & 40 & 36 & 29 & 25 & 22 & 20 & 16 & 11 & 8 \\ \text { AVR } & 44 & 36 & 31 & 25 & 22 & 19 & 16 & 13 & 10 & 8\end{array}$

FIGURE 3. Kaplan-Meier survival curves comparing postoperative cardiovascular event-free survival among patients undergoing aortic valve $(A V)$ repair (solid line) or aortic valve replacement $(A V R)$ (dashed line). $C V$, Cardiovascular.

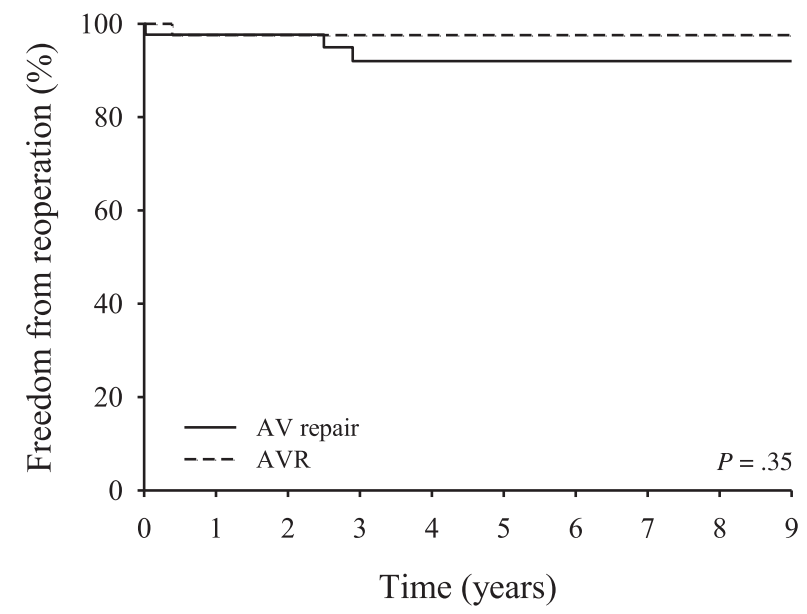

$\begin{array}{lllllllllll}\text { AV repair } & 44 & 41 & 38 & 32 & 28 & 25 & 23 & 22 & 14 & 10\end{array}$ $\begin{array}{lllllllllll}\text { AVR } & 44 & 37 & 32 & 29 & 23 & 20 & 17 & 15 & 13 & 12\end{array}$

FIGURE 4. Kaplan-Meier survival curve comparing freedom from aortic valve reoperations among patients undergoing aortic valve $(A V)$ repair (solid line) or aortic valve replacement (AVR) (dashed line).

procedures require a clear understanding of the functional anatomy of the AV and root to be successful. The early experience with these procedures was indeed quite disappointing, with as many as $30 \%$ of patients presenting with recurrent severe $\mathrm{AR}$ and eventually needing a reoperation. ${ }^{20,21}$ It soon became apparent that the primary cause of recurrent AR was the presence of a cuspal prolapse, which either was preexisting but went unrecognized, or was induced by the reduction of the sinotubular junction intraoperatively. ${ }^{22}$ These unsatisfactory results fostered the development of a variety of cuspal repair techniques aimed at correcting preexisting or surgically induced cusp prolapses. The systematic application of these techniques in the presence of any residual prolapse has markedly improved the outcome of valve-sparing aortic root replacement procedures ${ }^{23,24}$ and has laid the foundation for their use in patients with severe AR due to isolated type 2 AV dysfunction; that is, those with primary cuspal prolapses but without significant aortic root pathology. ${ }^{25,26}$ With increasing experience, the indication was even extended to patients with bicuspid aortic valve disease and those with type $3 \mathrm{AV}$ dysfunction, ${ }^{27-29}$ such as degenerative calcified AR, rheumatic AR, or AV endocarditis. Results for these newer indications have not been as robust as those reported in patients with type 1 and/or type 2 dysfunction, owing probably to the large amount of diseased tissue that has to be excised and to the use of biological patches to close the resulting defects. ${ }^{10,28}$ In bicuspid aortic valves, results have also been less longlasting when trying to respect an initially asymmetrical valve geometry ${ }^{28}$ or when reducing the size of the aortoventricular junction by use of subcommissural annuloplasty stiches. $^{29}$ 
The data reported in our study represent our first 15 years of experience with the use of AV repair surgery for the treatment of severe AR. It thus includes our initial learning curve as well as the many refinements in operative techniques that were introduced during the study period. Despite this, our data indicate that $\mathrm{AV}$ repair is associated with low operative mortality (around 1\%), good medium-term survival (87\% at 9 years), an acceptable risk of reoperation ( $8 \%$ at 9 years), and a relatively low cardiovascular event rate (32\% at 9 years). These results compare favorably with those reported by other investigators. In 274 patients undergoing AV repair for type $1 \mathrm{AV}$ dysfunction, including 46 patients undergoing operation for acute type A dissection, Aicher and colleagues ${ }^{23}$ reported an operative mortality of $3.6 \%$, a 5 -year overall survival of $91 \%$, and a $4 \%$ risk of reoperation at 5 years. The same authors subsequently reported their experience in 316 patients undergoing bicuspid AV repair, in whom operative mortality was only $0.6 \%$, 5 -year survival was $99 \%$, and the risk of reoperation at 5 years was $12 \% .^{28}$ Similarly good results were reported by Minakata and colleagues, ${ }^{7}$ in the meta-analysis of Carr and Savage, ${ }^{6}$ and more recently by Svensson and colleagues $^{30}$ and Sharma and colleagues. ${ }^{31}$ Altogether, the available data suggest that $\mathrm{AV}$ repair is a safe procedure, with good medium- to long-term results with respect to overall survival and risk of reoperation.

\section{Comparison With AVR}

Very few studies have compared the outcome of patients after AV repair or AVR and none have directly compared these 2 techniques. In their meta-analysis, Carr and Savage ${ }^{6}$ compared the results of $\mathrm{AV}$ repair with those of AVR using selected data from the literature. Their comparison suggested that the 2 approaches expose patients to a similar 5-year risk of reoperation, and that AV repair might be associated with better medium-term survival than bioprosthetic AVR. Although their results are quite similar to those reported in our study, their analysis was flawed by the large age difference between the patients undergoing AV repair and those undergoing AVR. More recently, Svensson and colleagues ${ }^{30}$ made a similar comparison between AV repair and bioprosthetic AVR, using premarket approval data for the Carpentier Edwards (Irvine, Calif) bovine pericardial aortic valve prosthesis. Although their data also suggested that AV repair results in a better long-term survival, their analysis was limited by the large age difference between members of the AV repair and AVR groups and by the fact that most patients who underwent AVR were operated on for severe aortic stenosis or combined stenosis and regurgitation $(80 \%)$, whereas a minority had isolated AR $(17 \%)$.

Our study is thus the first to provide a direct comparison between AV repair and AVR in patients with severe AR. To overcome the absence of randomization and compensate for the differences in baseline characteristics between our 2 treatment groups, we performed a propensity score analysis. The results of this analysis showed a large survival advantage in favor of patients undergoing $\mathrm{AV}$ repair compared with those undergoing AVR. Furthermore, our data also suggest a trend toward lower operative mortality with AV repair. Importantly, we also found that the improved outcome after AV repair was not obtained at the expense of a significant increase in valve-related complications. In particular, the rate of thromboembolism, severe bleeding, and endocarditis as well as the incidence of reoperation were quite small and did not significantly differ between AV repair and AVR.

\section{Limitations}

There are several limitations to our study that should be acknowledged. First, despite the completeness of our follow-up data and the prospective nature of the database from which the data were retrieved, our study has a retrospective design, patients were not randomized between $\mathrm{AV}$ repair and AVR, and the number of patients undergoing AVR in our series was relatively small. Although we used a propensity score analysis to compare long-term survival among matched pairs of patients, we cannot exclude the possibility that unaccounted for confounding factors contributed to our results. There is no doubt that a prospective randomized trial would provide a definite demonstration of the superiority of aortic reconstruction. Second, AV repair is a demanding procedure that is currently performed only in few high volume and highly specialized centers. Because this technique requires special skills and experience, one must be careful when translating our results to smaller or less experienced centers that have not had preliminary special training. Third, we used a semiquantitative multiparametric approach to assess AR severity. Although this integrated approach is recommended both by the American Society of Echocardiography ${ }^{13}$ and the European Association of Echocardiography, ${ }^{32}$ the absence of quantitative measures of AR severity, such as the regurgitant volume, the effective regurgitant orifice area, or both, could be viewed as a possible limitation. To address this issue, we analyzed separately the outcome of patients operated on before and after we started to systematically acquire quantitative parameters of AR severity in our echocardiographic laboratory; that is, in 2006. Although the follow-up is shorter for the period 2006 to 2010, the survival benefits conferred by AV repair were found to be similar between the periods 1995 to 2005 and 2005 to 2010 (data not shown).

\section{CONCLUSIONS}

Our study shows that after adjustment for all confounding variables using a multivariate analysis and a propensity score matching procedure, $\mathrm{AV}$ repair is a strong 
independent predictor of improved survival, with excellent freedom from reoperation, in comparison with AVR. These data suggest that $A V$ repair should be the preferred method of correction of AR and should be considered in all cases in which surgery is contemplated and the valve is considered to be repairable.

The authors thank Annie Robert, $\mathrm{PhD}$, for providing thoughtful statistical review and advice.

\section{References}

1. Bonow RO, Carabello BA, Chatterjee K, deLeon AC Jr, Faxon DP, Freed MD, et al. ACC/AHA 2006 guidelines for the management of patients with valvular heart disease: a report of the American College of Cardiology/American Heart Association Task Force on Practice Guidelines (writing Committee to Revise the 1998 guidelines for the management of patients with valvular heart disease). J Am Coll Cardiol. 2006;48:e1-148.

2. Vahanian A, Baumgartner H, Bax J, Butchart E, Dion R, Filippatos G, et al. Guidelines on the management of valvular heart disease: the Task Force on the Management of Valvular Heart Disease of the European Society of Cardiology. Eur Heart J. 2007;28:230-68.

3. Rahimtoola SH. Choice of prosthetic heart valve for adult patients. J Am Coll Cardiol. 2003:41:893-904.

4. Hammermeister K, Sethi GK, Henderson WG, Grover FL, Oprian C, Rahimtoola SH. Outcomes 15 years after valve replacement with a mechanical versus a bioprosthetic valve: final report of the Veterans Affairs randomized trial. J Am Coll Cardiol. 2000;36:1152-8.

5. Oxenham H, Bloomfield P, Wheatley DJ, Lee RJ, Cunningham J, Prescott RJ, et al. Twenty year comparison of a Bjork-Shiley mechanical heart valve with porcine bioprostheses. Heart. 2003;89:715-21.

6. Carr JA, Savage EB. Aortic valve repair for aortic insufficiency in adults: a contemporary review and comparison with replacement techniques. Eur J Cardiothorac Surg. 2004;25:6-15.

7. Minakata K, Schaff HV, Zehr KJ, Dearani JA, Daly RC, Orszulark TA, et al. Is repair of aortic valve regurgitation a safe alternative to valve replacement? J Thorac Cardiovasc Surg. 2004;127:645-53.

8. Langer F, Aicher D, Kissinger A, Wendler O, Lausberg H, Fries R, et al. Aortic valve repair using a differentiated surgical strategy. Circulation. 2004;110(Suppl II):II67-73.

9. Boodhwani M, El Khoury G. Principles of aortic valve repair. J Thorac Cardiovasc Surg. 2010;140(Suppl):S20-2.

10. Boodhwani M, de Kerchove L, Glineur D, Poncelet A, Rubay J, Astarci P, et al. Repair-oriented classification of aortic insufficiency: impact on surgical techniques and clinical outcomes. J Thorac Cardiovasc Surg. 2009;137: 286-94.

11. le Polain de Waroux JB, Pouleur AC, Goffinet C, Vancraeynest D, Van Dyck M, Robert A, et al. Functional anatomy of aortic regurgitation: accuracy, prediction of surgical repairability, and outcome implications of transesophageal echocardiography. Circulation. 2007;116:I264-9.

12. Aicher D, Fries R, Rodionycheva S, Schmidt K, Langer F, Schäfers HJ. Aortic valve repair leads to a low incidence of valve-related complications. Eur $J$ Cardiothorac Surg. 2010;37:127-32.

13. Zoghbi WA, Enriquez-Sarano M, Foster E, Grayburn PA, Kraft CD, Levine RA, et al. Recommendations for evaluation of the severity of native valvular regurgitation with two-dimensional and Doppler echocardiography. J Am Soc Echocardiogr. 2003;16:777-802.
14. Rosenbaum PR, Rubin DB. The central role of the propensity score in observational studies for causal effects. Biometrika. 1983;70:41-55.

15. Joffe MM, Rosenbaum PR. Invited commentary: propensity scores. Am J Epidemiol. 1999;150:327-33.

16. Lang RM, Bierig M, Devereux RB, Flashskampf FA, Foster E, Pellikka PA, et al. Recommendations for chamber quantification: a report from the American Society of Echocardiography's guidelines and standards committee and the chamber quantification writing group. J Am Soc Echocardiogr. 2005;18: 1440-63.

17. Enriquez-Sarano M, Schaff HV, Orszulak TA, Tajik AJ, Bailey KR, Frye RL. Valve repair improves the outcome of surgery for mitral regurgitation. A multivariate analysis. Circulation. 1995;91:1022-8.

18. Sarsam MA, Yacoub M. Remodeling of the aortic valve anulus. J Thorac Cardiovasc Surg. 1993;105:435-8.

19. David TE, Feindel CM. An aortic valve-sparing operation for patients with aortic incompetence and aneurysm of the ascending aorta. J Thorac Cardiovasc Surg. 1992;103:617-21.

20. Luciani GB, Casali G, Tomezzoli A, Mazzucco A. Recurrence of aortic insufficiency after aortic root remodeling with valve preservation. Ann Thorac Surg. 1999;67:1849-52.

21. Leyh RG, Fischer S, Kallenbach K, Kofidis T, Pethig K, Harringer W, et al. High failure rate after valve-sparing aortic root replacement using the "remodeling technique" in acute type A aortic dissection. Circulation. 2002;106(Suppl 1): I229-33.

22. le Polain de Waroux JB, Pouleur AC, Robert A, Pasquet A, Gerber BL, Noirhomme $\mathrm{P}$, et al. Mechanisms of recurrent aortic regurgitation after aortic valve repair: predictive value of intraoperative transesophageal echocardiography. JACC Cardiovasc Imaging. 2009;2:931-9.

23. Aicher D, Langer F, Lausberg H, Bierbach B, Schäfers HJ. Aortic root remodeling: ten-year experience with 274 patients. J Thorac Cardiovasc Surg. 2007;134: 909-15.

24. Jeanmart H, de Kerchove L, Glineur D, Goffinet JM, Rougui I, Van Dyck M, et al. Aortic valve repair: the functional approach to leaflet prolapse and valve-sparing surgery. Ann Thorac Surg. 2007;83(Suppl):S746-51.

25. Schäfers HJ, Aicher D, Langer F. Correction of leaflet prolapse in valvepreserving aortic replacement: pushing the limits? Ann Thorac Surg. 2002; 74(Suppl):S1762-4.

26. de Kerchove L, Glineur D, Poncelet A, Boodhwani M, Rubay J, Dhoore W, et al. Repair of aortic leaflet prolapse: a ten-year experience. Eur J Cardiothorac Surg. 2008;34:785-91.

27. El Khoury G, Vanoverschelde JL, Glineur D, Pierard F, Verhelst RR, Rubay J, et al. Repair of bicuspid aortic valves in patients with aortic regurgitation. Circulation. 2006;114:I610-6.

28. Aicher D, Kunihara T, Abou Issa O, Brittner B, Gräber S, Schäfers HJ. Valve configuration determines long-term results after repair of the bicuspid aortic valve. Circulation. 2011;123:178-85.

29. de Kerchove L, Boodhwani M, Glineur D, Vandyck M, Vanoverscheide JL, Noirhomme P, et al. Valve sparing-root replacement with the reimplantation technique to increase the durability of bicuspid aortic valve repair. $J$ Thorac Cardiovasc Surg. 2011;142:1430-8.

30. Svensson LG, Batizy LH, Blackstone EH, Gillinov AM, Moon MC, D'Agostino RS, et al. Results of matching valve and root repair to aortic valve and root pathology. J Thorac Cardiovasc Surg. 2011;142:1491-8.

31. Sharma V, Suri RM, Dearani JA, Burkhart HM, Park SJ, Joyce LD, et al. Expanding relevance of aortic valve repair-is earlier operation indicated? J Thorac Cardiovasc Surg. 2014;147:100-8.

32. Lancellotti P, Tribouilloy C, Hagendorff A, Moura L, Popescu BA, Agricola E, et al. European Association of Echocardiography recommendations for the assessment of valvular regurgitation. Part 1: aortic and pulmonary regurgitation (native valve disease). Eur J Echocardiogr. 2010;11:223-44. 